\title{
EXPERIMENTAL VALIDATION OF THE SENSING CAPABILITIES OF TUNABLE INTERDIGITAL TRANSDUCER
}

\author{
Michał MAŃKA \\ AGH University of Science and Technology, \\ Faculty of Mechanical Engineering and Robotics, Department of Robotics and Mechatronics \\ al. A. Mickiewicza 30, 30-059 Krakow, Poland \\ mmanka@agh.edu.pl
}

\begin{abstract}
Modern systems and methods of Structural Health Monitoring (SHM) and Non Destructive Testing (NDT) require new types of transducers. In this paper, a new type of Lamb Wave transducer, the Tunable Interdigital Transducer (T-IDT), developed at AGH University of Science and Technology, is presented and its sensing capabilities are discussed based on experimental tests. The properties of the proposed transducer are similar to those of a traditional Interdigital Transducer (IDT), except for its ability to change the wavelength to which the transducer is tuned without introducing any physical changes in the electrode layout. In the paper, three sets of experiments are presented. The first two determine the ability of the transducer to measure the distance of damage from the transducer. The last set of experiments investigates the angular sensitivity of the proposed transducer for modelled damage. The presented results are compared to ones obtained with a traditional IDT.
\end{abstract}

Keywords: IDT, Lamb Wave, Transducer, SHM, NDT

\section{DOSTRAJALNY PRZETWORNIK MIĘDZYPALCZASTY, T-IDT, BADANIA EKSPERYMENTALNE ZDOLNOŚCI DO WYKRYWANIA USZKODZEŃ}

\begin{abstract}
Streszczenie
Nowoczesne systemy i metody Monitorowania Stanu Konstrukcji (ang. SHM) oraz techniki Badań Nieniszczących (ang. NDT) wymagają opracowywania coraz to nowszych typów przetworników. W artykule został przedstawiony nowy typ przetwornika do badań z wykorzystaniem fal powierzchniowych Lamb'a, opracowany na Akademii Górniczo-Hutniczej w Krakowie a nazwany przez jego twórców Dostrajalnym Przetwornikiem Międzypalczastym (ang. T-IDT). Właściwości prezentowanego przetwornika T-IDT są zbliżone do właściwości tradycyjnego IDT z jedną różnicą mianowicie przetwornik T-IDT może zostać dostrojony do określonej długości fali bez potrzeby wprowadzania zmian w jego strukturze. W artykule zostały przedstawione trzy serie eksperymentów dotyczących badań zdolności przetwornika do wykrywania uszkodzeń. W pierwszych dwóch seriach badana była zdolność przetwornika do wykrywania i określenia odległości uszkodzenia od przetwornika. Natomiast trzecia seria badań dotyczyła czułości przetwornika na uszkodzenie w zależności od jego pozycji kątowej względem przetwornika. Wszystkie wyniki eksperymentów uzyskane $\mathrm{z}$ zastosowaniem przetworników T-IDT zostały porównane $\mathrm{z}$ wynikami uzyskanymi z wykorzystaniem tradycyjnych przetworników IDT.
\end{abstract}

Słowa kluczowe: IDT, Przetwornik Międczypalczasty, Fale Lamb’a, Monitorowanie Stanu Konstrukcji, Badania Nieniszczące

\section{INTRODUCTON}

In recent decades, Structural Health Monitoring (SHM) systems have become an integral part of modern structures. Currently, it is very rare to find a modern system without a proper damage detection section. For this purpose, many different physical phenomena are adapted in order to extract useful diagnostic data. Many different types of transducers used for Non-Destructive Testing (NDT) are also currently applied in SHM and new types of transducers are being developed [1,2,3].
One of the groups of methods frequently used for system condition evaluation are those based on ultrasonic surface waves, especially Lamb Waves (LWs). LWs are an elastic type of wave that may be excited and which propagate in thin platelike structures and are guided by its boundaries. Any material discontinuities present in the structure interact with LWs and therefore may be detected by proper sensors. Details concerning LWs and their implementation in SHM systems may be found in the work of Raghavan and Cesnick [4]. The most frequently used type of transducer in SHM systems based on LWs are transducers based on lead 
zirconate titanate (PZT) ceramics. They are usually designed as multi-modal, omnidirectional wave sources [5] and their mode selectivity, dominant frequency and main directions of propagation are strictly connected with their geometrical dimensions [6]. Unfortunately, such a signal is very hard to interpret and requires complex electronics as well as advanced algorithms for signal generation and reception $[7,8,9,10]$. The application of PZT ceramics as piezoelectric material in transducers whose dimensions exceed tens of millimetres, i.e. in IDTs, is significantly limited to ones where the tested structure does not deform significantly during normal operational conditions.

One group of materials that offers elasticity connected with high energy wave generation consists of piezocomposites. Commercially available piezocomposites based on Macro-fiber (MFC) [11] and Active fiber (AFC) [12] composites offer high-energy transfer ability combined with flexibility [13].

Based on previous research, the most promising type of transducers for SHM application are narrowband, directional ones, which allow most of the wave energy to be focused in a limited bandwidth and in the desired direction. An example of such a transducer is an Interdigital Transducer (IDT), which offers the ability to tune to desired frequencies and focus the wave in a single direction. This type of transducer, based both on PZT and MFC piezoelectric materials, has been widely discussed in many publications, including the author's previous works $[13,14,15,16]$.

In the presented paper, a traditional IDT transducer and a new type of transducer, called a Tunable Interdigital Transducer (T-IDT), are compared in terms of their sensing capabilities.

The paper is organized as follows. After a short introduction in Section 1, Section 2 contains a presentation of the IDT and the developed T-IDT transducers. A prototype of the T-IDT and experimental setup is briefly described in Section 3. Experimental results are reported and compared with a traditional IDT in Sections 4 and 5. Finally, Section 6 presents the author's conclusions.

\section{MFC BASED T-IDT}

Developed in the Department of Robotics and Mechatronics, AGH, a Tunable Interdigital Transducer (T-IDT) $[16,17,15,18]$ is a very promising construction that combines the advantages of IDT, namely narrowband wave generation and its directivity, with the elasticity of MFC transducers and the ability to tune to desired wavelengths without physical changes in the electrode layout or complex excitation methods.

A traditional IDT is optimized for a particular wavelength by adjusting the distance between the comb electrodes located on one side, in a singlesided version, or both sides, in a double-sided version, of the piezoelectric layer, as shown in Figure $1[13,14]$.

The main disadvantage of such a design is that the wavelength to which the transducer is tuned may be defined only during the manufacturing process, when electrodes are deposited. In order to overcome this drawback, a new type of transducer was developed [18].

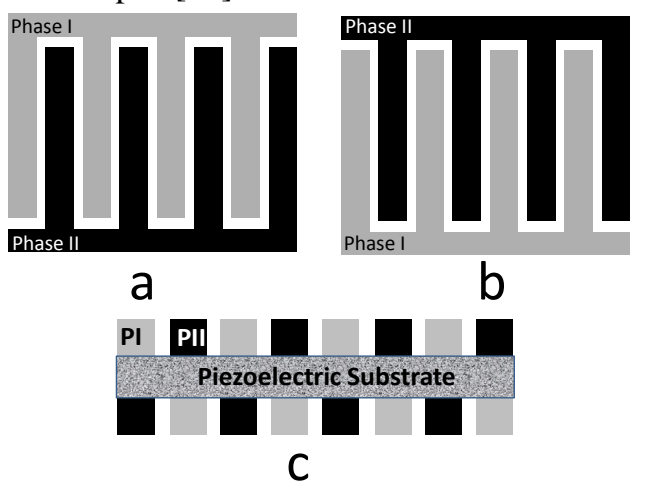

Fig. 1. Electrode layout of the traditional double sided IDT: (a) top electrode, (b) bottom electrode, and (c) cross-section

In the proposed design, comb electrodes present in IDT (Figure $1 \mathrm{a}-\mathrm{b}$ ) were replaced by densely distributed stripe electrodes that may cover both sides of the transducer (Figure 2). Electrode stripes may be easily connected into groups that form a layout similar to the traditional IDT's electrodes, but, contrary to it, may be easily changed after the transducer is manufactured (Figure $2 \mathrm{a}-\mathrm{b}$ ).
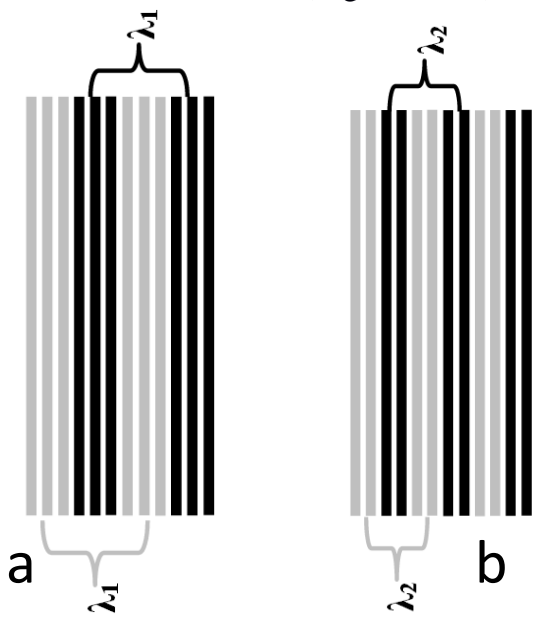

Fig. 2. T-IDT a). electrode layout in configuration 1 b). electrode layout in configuration 2

In order to verify the theoretical properties of the proposed T-IDT transducer, the numerical and experimental prototypes were designed and tested (Figure 3) [16]. In the proposed prototype, the width of the discrete electrode stripes is $\mathrm{W}_{\mathrm{E}}=0.4 \mathrm{~mm}$ and the distance between the electrodes equals $D_{E}=0.1 \mathrm{~mm}$. The total number of discrete electrodes in the presented design is 92 per single side and each of the electrodes is connected with a separate soldering pad which ensures proper connection to the ribbon cables. The dimension of 
the active area of the designed T-IDT is equal to: $\mathrm{Wa}=21 \mathrm{~mm} \mathrm{La}=45.9 \mathrm{~mm}$ and the total dimension $\mathrm{Wp}=59 \mathrm{~mm}$ and $\mathrm{Lp}=60.1 \mathrm{~mm}$ (Figure 3). The proposed design allows the transducer to be tuned to the desired wavelength with a resolution of 1 $\mathrm{mm}$.

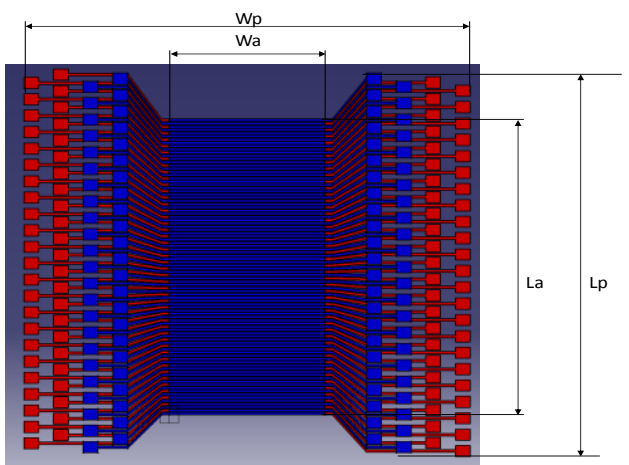

Fig. 3. T-IDT design of the prototype

The initial results presented in $[15,16]$ proved that the proposed T-IDT can be used as a high performance source of Lamb waves, with similar properties to the traditional IDT. However, contrary to the traditional IDT, it may be easily tuned to the desired wavelength of the excited wave without changes in the electrode layout. Exemplary results of initial research are presented in Figures 4-6.

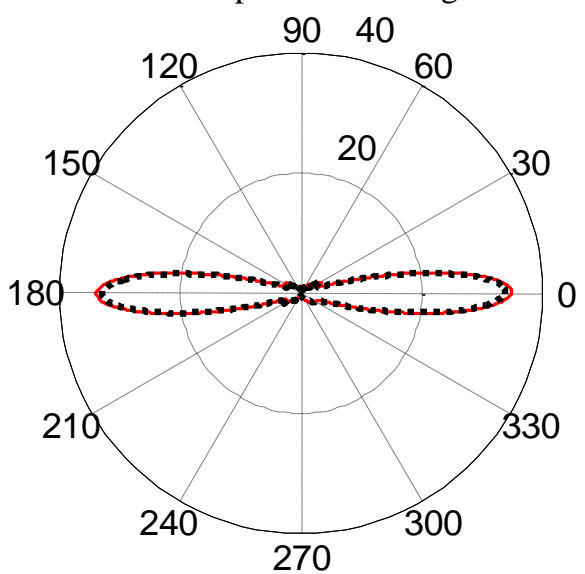

Fig. 4. Simulated beampatterns of the IDT (solid line) and T-IDT (dotted line) for the frequency of $300 \mathrm{kHz}$ (c)

\section{EXPERIMENTAL TEST RIG FOR DETERMINING THE SENSING CAPA- BILITIES OF THE MFC BASED T-IDT}

To identify the sensing capabilities of the designed transducer, experimental tests of the transducer mounted on an aluminium plate were performed. In the presented tests, the T-IDT was mounted on a $1000 \times 1000 \times 4 \mathrm{~mm}$ aluminium plate using Loctite 3430 epoxy adhesive. The transducer's electrodes were connected into groups corresponding to the wavelength of $8 \mathrm{~mm}$, as presented in Figure 7 below.

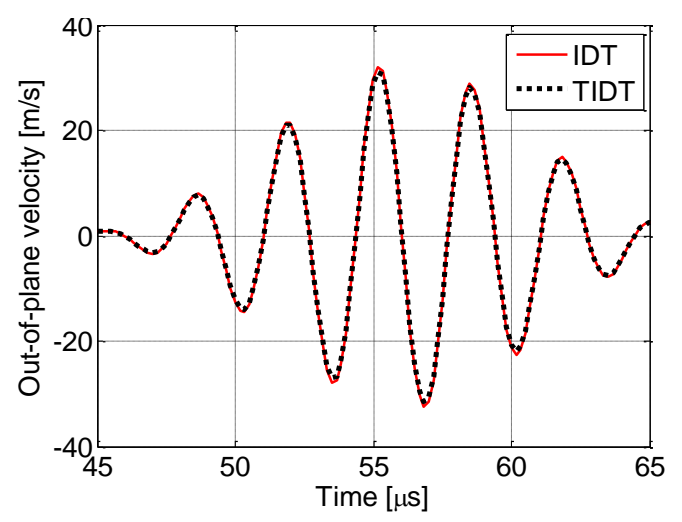

Fig. 5. The out-of-plane vibrations obtained during numerical simulations of IDT (solid line) and T-IDT (dotted line) at the excitation frequency of $300 \mathrm{kHz}$ in the direction perpendicular to interdigital electrodes

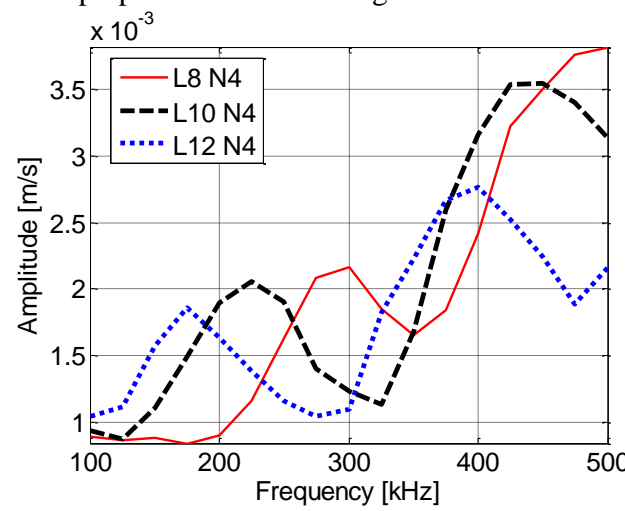

Fig. 6. Maximum amplitudes of simulated waves registered at different excitation frequencies and for different configurations of T-IDT

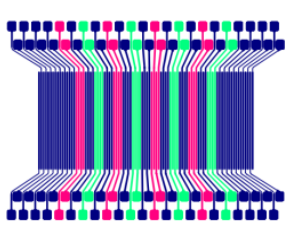

a

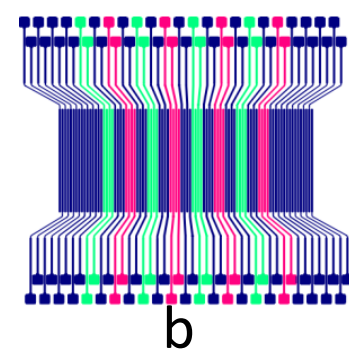

Fig. 7. Configurations of the designed T-IDT for experimental tests; a.) top electrodes b.) bottom electrodes

For the chosen electrode layout, nominal frequencies for each of the modes (Symmetric and Antisymmetric) may be calculated based on dispersion plots. In the chosen configuration, only 3 modes corresponding to the electrode layout are present: two Antisymmetric (A0 and A1) and one Symmetric (S0), as presented in Table 1.

Table 1. Wavelength and corresponding nominal frequencies of the designed T-IDT transducer

\begin{tabular}{|c|c|}
\hline Wavelength $\lambda$ & Nominal frequencies \\
\hline \multirow{2}{*}{$8 \mathrm{~mm}$} & $\mathrm{~A} 0-303 \mathrm{kHz}$ \\
& $\mathrm{S} 0-548 \mathrm{kHz}$ \\
$\mathrm{A} 1-743 \mathrm{kHz}$ \\
\hline
\end{tabular}


During the experiments, a computer with the LabView software connected to the NI PXI system was used. In the first set of experimental tests, an IDT, based on the MFC substrate, was used as the Lamb Wave source. The transducer was connected with two NI PXI-5412 arbitrary waveform generators, via Trek HF-2100, highvoltage power amplifiers (Figure 8). Additionally, a PXI-5922 24-bit digital oscilloscope was connected with the T-IDT to measure the waves excited in the plate.

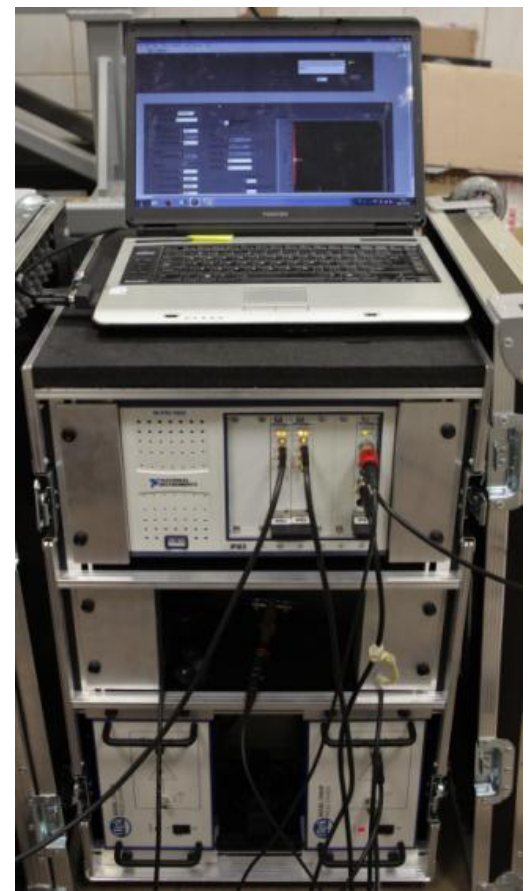

Fig. 8. Computer with LabView connected to the PXI system with a signal generator and voltage amplifier used in the experimental test

Both transducers, IDT and T-IDT, were mounted on opposite sides of the plate, at a distance of $300 \mathrm{~mm}$ from its border (Figure 9). In order to identify the influence of material discontinuity, possible damage of the structure, on the wave travelling in the plate, a magnet and ferromagnetic pad were temporarily mounted at the distance of $150 \mathrm{~mm}$ from the centres of the transducers.

The parameters of the excitation signals used during the experiments were the same as during previous tests [16]: the amplitude was set to $100 \mathrm{Vp}-\mathrm{p}$ and the five-cycle tone burst modulated by a Hanning window was used as the excitation signal. The tests were performed in the frequency range from 200 to $500 \mathrm{kHz}$ with a step of $50 \mathrm{kHz}$.

In addition, the environmental parameters during all of the performed tests were kept at a constant level. Temperature in the laboratory was $22^{\circ}$ Celsius and humidity was $45 \%$. Delays between each excitation pulse were also set at $1 \mathrm{~s}$, ensuring that the temperature of the transducers was at a constant level and the influence of temperature changes can be neglected in the analysis.

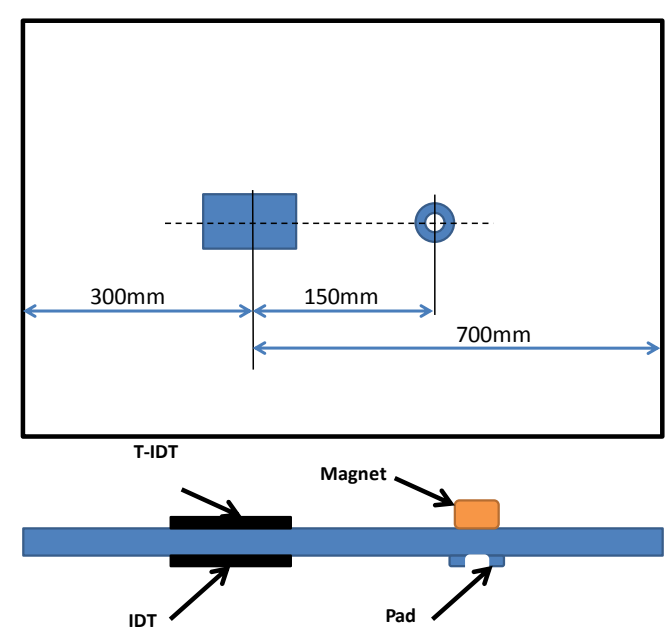

Fig. 9. Scheme of the test rig

\section{DISTANCE DETECTION CAPABILITY}

During the experimental tests, a Pitch-catch method was adapted in order to identify the damage sensitivity of the T-IDT transducer.

In the first set of experiments, the IDT was connected to the arbitrary wave generator, acting as the Lamb Waves emitter, and the T-IDT connected to the oscilloscope as a sensor.

First, the response of the undamaged structure was measured, without the magnet and pad mounted on the plate. A series of tests was performed with different excitation frequency in order to obtain a set of reference measurements. Exemplary results obtained with the excitation frequency of $300 \mathrm{kHz}$ are presented in Figure 10.

At the frequency of $300 \mathrm{kHz}$ the excited wave mode $\mathrm{A} 0$ has a length corresponding to the distance between electrode groups and is equal to $8 \mathrm{~mm}$, therefore its amplitude is significantly increased and this mode is the main component of the excited wave. As can be seen in Figure 10, two main peaks are visible on the time plot at $200 \mu \mathrm{s}$ and $470 \mu \mathrm{s}$. The source of the first peak is the wave reflected from the closer border of the plate at the distance of $300 \mathrm{~mm}$ and the second is the reflection from the border at the distance of $700 \mathrm{~mm}$. Based on these measurements, the speed of the dominant mode of the wave travelling in the plate may be calculated as presented in Table 2 .

Table 2. Calculated velocity of the wave travelling in a $4 \mathrm{~mm}$ aluminium plate

\begin{tabular}{|c|c|c|}
\hline $\begin{array}{c}\text { Mode@ } \\
\text { Frequency } \\
{[\mathrm{kHz}]}\end{array}$ & $\begin{array}{c}\text { Velocity based on } \\
\text { dispersion plot } \\
{[\mathrm{km} / \mathrm{s}]}\end{array}$ & $\begin{array}{c}\text { Velocity based on } \\
\text { TOF }[\mathrm{km} / \mathrm{s}]\end{array}$ \\
\hline A0@300 & 3.14 & 3.17 \\
\hline
\end{tabular}

The theoretical speed of the A0 mode at the frequency of $300 \mathrm{kHz}$ in the $4 \mathrm{~mm}$-thick aluminium plate based on dispersion curves $[13,16]$ is $3.14 \mathrm{~km}$ per second and is comparable to the speed calculated based on the time-of-flight (TOF), which is $3.17 \mathrm{~km} / \mathrm{s}$, measured during experiments. 


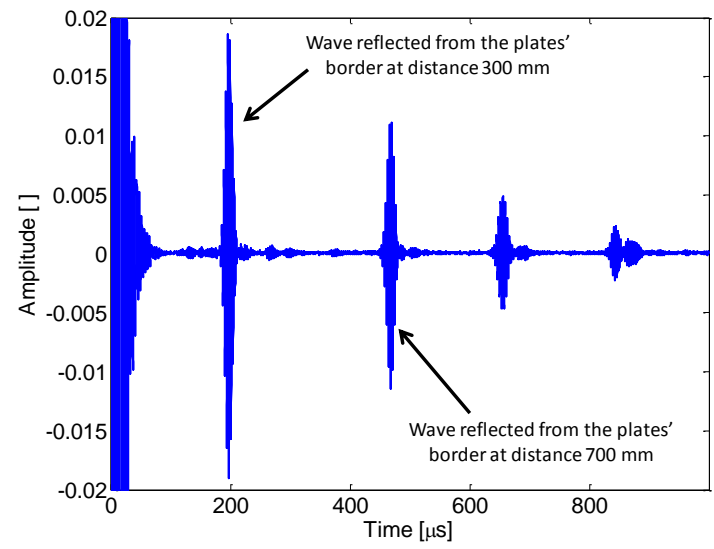

Fig. 10. The T-IDT measurements of the wave reflected from the borders of the aluminium plate at the excitation frequency of $300 \mathrm{kHz}$

Next, the "damage" modelled by the magnet and ferromagnetic pad were introduced to the aluminium plate and the experiments were repeated. The results obtained for the damaged and undamaged plate at the frequency of $300 \mathrm{kHz}$ are presented in Figure 11.

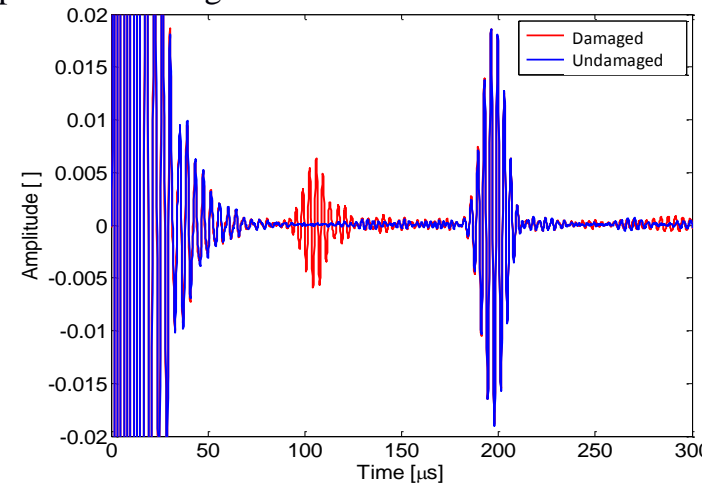

Fig. 11. The T-IDT measurements of the wave for the damaged and undamaged plate at the excitation frequency of $300 \mathrm{kHz}$

As can be seen, additional wave packages appear in the measurements obtained on the plate with the magnet and pad mounted, with the maximum of the package observed at $105 \mu \mathrm{s}$. Based on the group velocity, calculated in the previous experiments, the localization of the source of this package on the plate was calculated as presented in Table 3.

Table 3. Position of the damaged introduced to the plate

\begin{tabular}{|c|c|c|}
\hline $\begin{array}{c}\text { Mode@ } \\
\text { Frequency } \\
{[\mathrm{kHz}]}\end{array}$ & $\begin{array}{c}\text { Position based on } \\
\text { dispersion plot group } \\
\text { velocity [mm] }\end{array}$ & $\begin{array}{c}\text { Position based } \\
\text { on calculated } \\
\text { TOF Velocity } \\
{[\mathrm{mm}]}\end{array}$ \\
\hline $\mathrm{A} 0 @ 300$ & $298.3 / 2=149.15$ & $302.2 / 2=151.10$ \\
\hline
\end{tabular}

In both cases, the distance of the wave travelled in the time of $105 \mu \mathrm{s}$ is equal $\sim 300 \mathrm{~mm}$, and assuming that the position of the IDT and T-IDT are the same, the position of the discontinuity is at the distance of $\sim 150 \mathrm{~mm}$ from the transducer, at the same distance where the magnet was located. Based on the dispersion plots $[13,16]$ at the frequency of
$300 \mathrm{kHz}$, two modes are present, $\mathrm{A} 0$ and $\mathrm{S} 0$. Moreover, the shape of the pad, circular with a hole in the centre, generates the complex shape of the wave reflected from the modelled damage, resulting in at least three packages visible between 90 and $150 \mu \mathrm{s}$.

Experiments performed with different excitation frequency proved that the presence of discontinuity may be determined in all of the tested frequencies (Figure 12). However, the best resolution and highest response can be achieved at frequencies close to the nominal one, in the presented case being $300 \mathrm{kHz}$. At the frequencies significantly different from the nominal one, the wave is composed of several modes, i.e. A0, S0, A1 etc., whose group velocity and wavelength differ, extending the complexity and length of the wave package and significantly reducing the resolution of the discontinuity position detection.

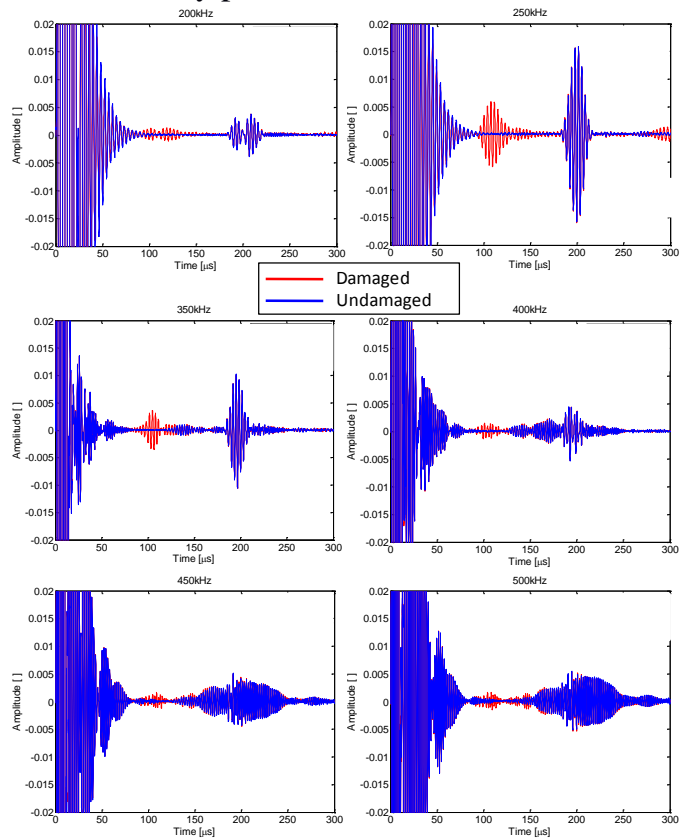

Fig. 12. Exemplary T-IDT measurements of the wave for the damaged and undamaged plate at different excitation frequencies

In the second set of experiments, both excitation and measurements were performed using the T-IDT transducer. Electrodes unused during excitation were connected to the oscilloscope in the configuration presented in Figure 13.

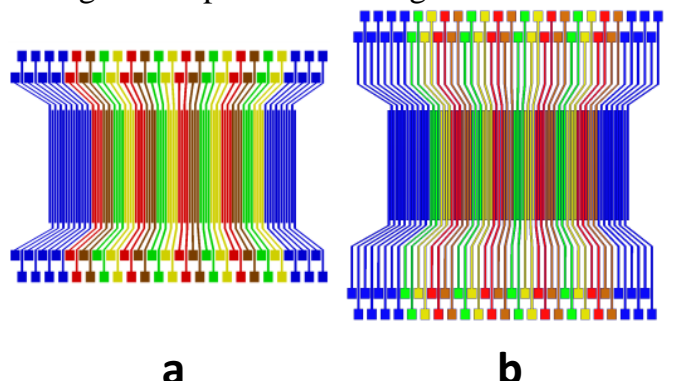

Fig. 13. Configurations of the designed T-IDT for experimental tests;

a.) top electrodes b.) bottom electrodes 
The green and red electrodes are connected to the arbitrary wave generator, while the brown and yellow ones are connected to the oscilloscope in order to acquire the response of the plate to the excited wave.

The results obtained at the excitation frequency of $300 \mathrm{kHz}$ are presented in Figure 14.
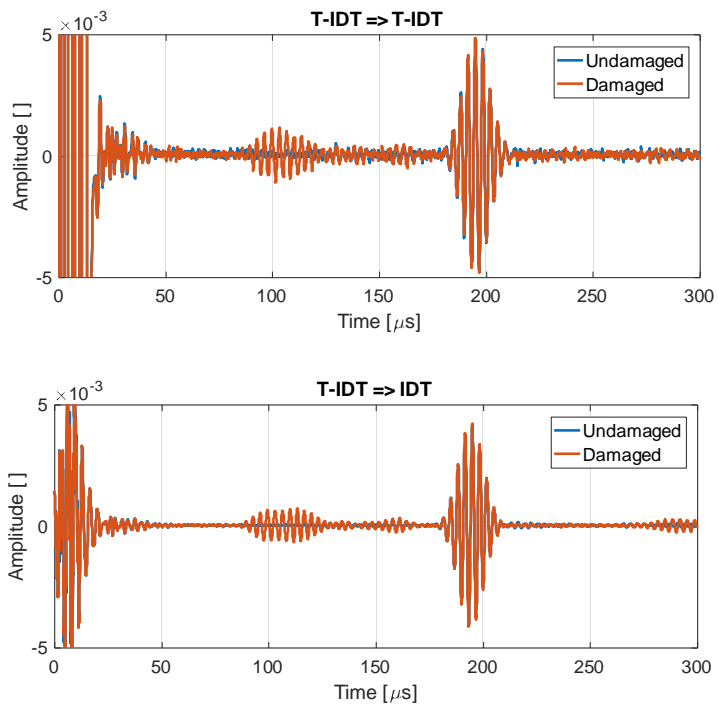

Fig. 14. Exemplary results of experimental tests in different emitter-sensor configuration at excitation frequency of $300 \mathrm{kHz}$

In order to compare the behaviour of the T-IDT with the IDT, signals excited by the T-IDT were measured by both transducers, T-IDT and IDT, at the same time. The results obtained for the configuration where the signal was excited and measured by the T-IDT is presented on the top plot in Figure 14, while the signal measured by the IDT is presented on the bottom plot. The signals obtained during experiments are very similar in shape and amplitude. A significantly higher amplitude of the excitation signal measured by the T-IDT and slight differences in the shape and amplitude of the signals reflected from the borders and magnet with the pad are the only visible differences. Comparison with the results from the previous experiment at the frequency of $300 \mathrm{kHz}$ presented in Figure 11 also confirms that the sensing capabilities of the T-IDT transducer are very similar to the ones offered by the traditional design of the IDT.

In this set of experiments, except the frequency of $300 \mathrm{kHz}$, other frequencies in the range of $200 \mathrm{kHz}$ to $500 \mathrm{kHz}$ were also tested. In all of the tested frequencies, the signals obtained in all emitter-sensor configurations are very similar, which proves that the properties of the proposed T-IDT transducer are close to those of a traditional one.

\section{ANGULAR DETECTION CAPABILITY}

The aim of the third set of experimental tests was to determine the angular sensitivity of the proposed transducer to the damage localisation. The experimental setup, including the excitation signal, was the same as previously with only the localisation of the pad being changed between each test.

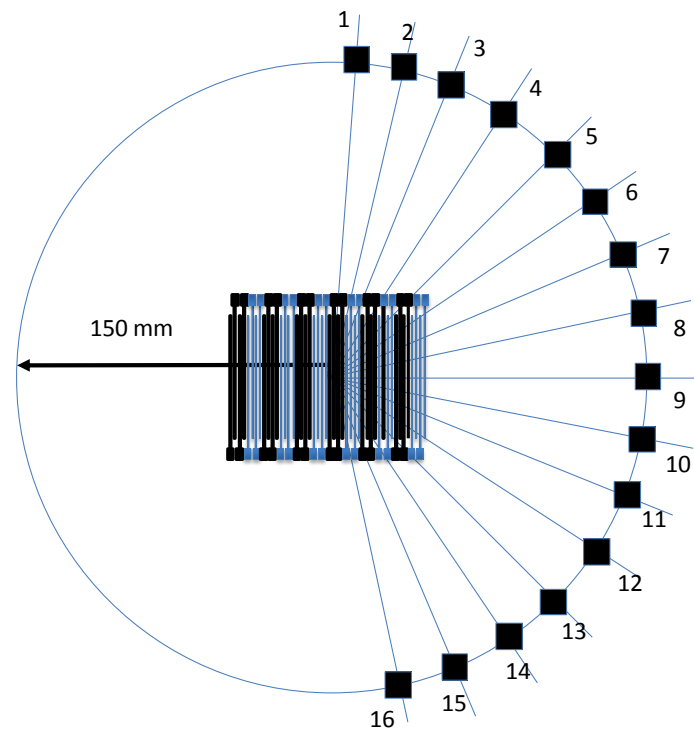

Fig. 15. Scheme of the test rig for angular sensitivity of the T-IDT

In this set of tests, the position of the pad was changed in the range of $-80^{\circ}$ to $+70^{\circ}$ with steps of $10^{\circ}$. Position $0^{\circ}$ (referred to as 9 in Figure 15) was localised in front of the transducer, perpendicularly to the interdigital electrodes, similarly to the previous experiments.

Exemplary results obtained during experimental tests, with the excitation frequency of $300 \mathrm{kHz}$, are presented in Figure 16.

In order to improve the visibility of the changes, only parts of the time-plots where the reflected signal should be visible, the time span between 80 and $180 \mu \mathrm{s}$, are presented.

As is visible, the position of the "damage" modelled as the pad has a significant influence on the shape and amplitude of the reflected wave.

The sensitivity of the transducer rapidly drops with changes of the angular position of the pad, which is presented in Figure 17. These results are similar to ones obtained with the traditional IDT transducer [14] ], as presented in Figure 18. In order to compare the results, the divergence angles for both of the transducers were calculated. The divergence angle, also known as the main lobe width, was calculated as a $-6 \mathrm{~dB}$ amplitude drop for each measurement. In the case of the IDT transducer, with a similar dimension [14], the calculated divergence angle was equal to $27^{\circ}$, while for the presented T-IDT transducer it was $34^{\circ}$. 


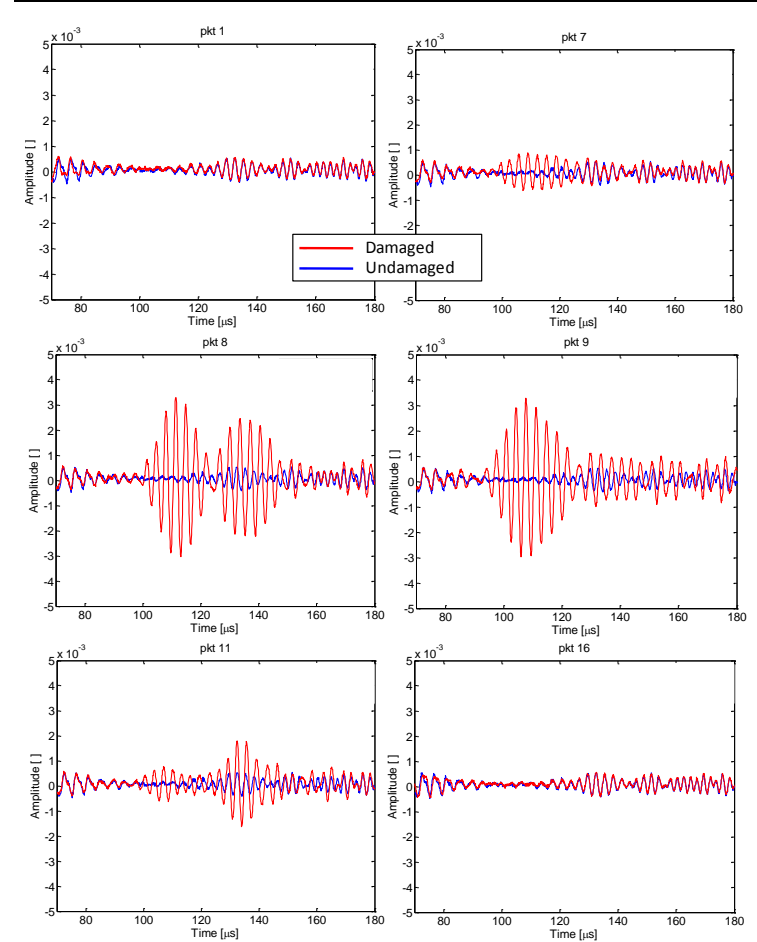

Fig. 16. Exemplary T-IDT measurements for different pad localisations at the excitation frequency of $300 \mathrm{kHz}$

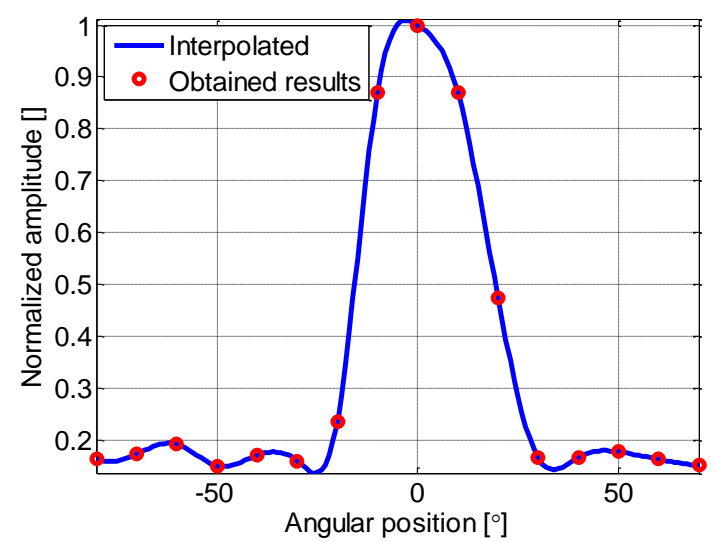

Fig. 17. Measured T-IDT angular sensitivity and its interpolation.

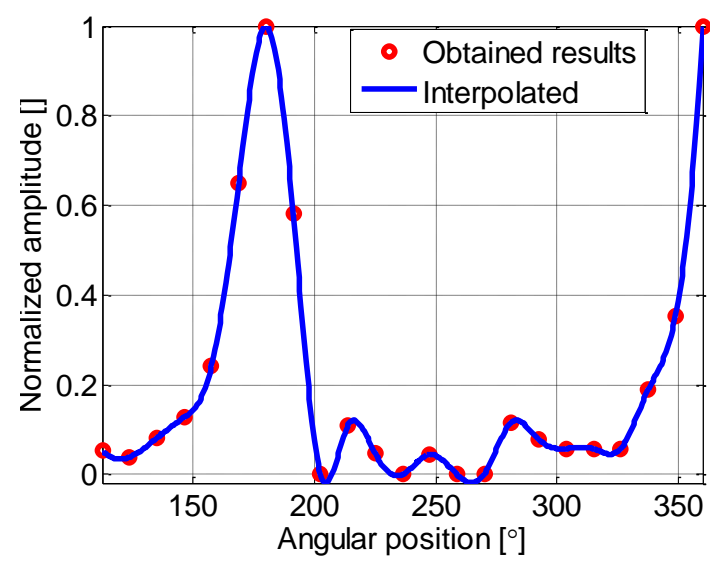

Fig.18. Measured IDT's angular sensitivity and its interpolation

\section{DISCUSSION AND CONCLUSIONS}

The experimental tests presented in the paper prove the ability of the presented transducer to detect damage localised in monitored structures. A new type of piezoelectric transducer proposed by the Department of Robotics and Mechatronics, AGH,

T-IDT combines the capability of narrowband directional wave excitation with the ability to change the nominal frequency a transducer is tuned to without introducing changes in its structures. The behaviour of the transducer in all of the tested frequencies and configurations are very similar to the behaviour of the traditional IDT. Both the amplitude levels and angular sensitivities of the transducers are comparable.

Based on the conducted experiments, the conclusion that the T-IDT transducer may be successfully used in all applications where a typical IDT transducer is suitable may be drawn. The main advantage of the proposed transducer over a traditional IDT is its ability to change its configuration without changing the electrode layout. The proposed design of the transducers allows transducers to be manufactured in large numbers and then their configuration to be adapted on site, without designing and manufacturing transducers for each application separately. This may lead to significant reductions in costs and the time of implementation.

During further research, the sensing capabilities in different transducer configurations will be investigated, including multiphase excitation and sensing of the Lamb Wave.

\section{REFERENCES}

1 Salas KI, Cesnik CES. Guided wave excitation by a CLoVER transducer for structural health monitoring: theory and experiments. Smart Material and Structures. 2009:1-27.

2 Salas KI, Cesnik CES. Design and Characterization of the CLoVER Transducer for Structural Health Monitoring. In: Procedings of SPIE; 2008.

3 Staszewski WJ. Health and usage monitoring of aerospace structures. Diagnostyka. 2004: 105-112.

4 Raghavan A, Cesnik CES. Review of Guided-wave Structural Health Monitoring. The shock and vibration digest. 2007, March; 2(39):91-114.

5 Klepka A, Ambroziński Ł. Selection of piezoceramic sensor parameters for damage detection and localization system. Diagnostyka. 2010:17-22.

6 Collet M, Ruzzene M, Cunefare KA. Generation of Lamb waves through surface mounted macro-fiber composite transducers. Smart Materials and Structures. 2011:1-14.

7 Ochoński J, Ambroziński Ł, Klepka A, Uhl T, Stępiński T. Choosing an appopriate sensor for the designed SHM system based on Lamb waves propagation. In: 11th IMEKO TC 10 workshop on Smart diagnostics of structures, Krakow, October 18-20, 2010. 
8 Dworakowski Z, Ambrozinski Ł, Packo P, Dragan K, Stepinski T. Application of artificial neural networks for compounding multiple damage indices in Lambwave-based damage detection. Structural Control and Health Monitoring. 2014; 22(1): 50-61. http://dx.doi.org/10.1002/stc.1659.

9 Klepka A, Ambroziński Ł. Selection of piezoceramic sensor parameters for damage detection and localization system. Selection of piezoceramic sensor parameters for damage detection and localization system. 2010;4(56):17-22.

10 Zima B, Rucka M. Application of wavelet transform in analysis of guided wave propagation signals for damage detection in a steel plate. Diagnostyka. 2015;16(2):43-48.

11 High JW, Wilkie KW. Method of fabricating NASAftandard Macro-Fiber Composite piezoelectric actuator. NASA Langley Research Center; 2003. NASA/TM-2003-212427 ARL-TR-2833.

12 Bent AA, Hagood NW. Piezoelectric Fiber Composites with Interdigitated Electrodes. Journal of Intelligent Material Systems and Structures. 1997:903-919.

13 Manka M, Rosiek M, Martowicz A, Stepinski T, Uhl T. Lamb wave transducers made of piezoelectric macro-fiber composite. Structural Control and Health $\begin{array}{lll}\text { Monitoring. } & \text { 2013: }\end{array}$ http://dx.doi.org/10.1002/stc. 1523

14 Stepinski T, Uhl T, Staszewski W. Advanced structural damage detection: from theory to engineering applications. John Wiley \& Sons; 2013.

15 Stepinski T, Manka M, Martowicz A. Interdigital Lamb Wave Transducers for Applications in Structural Health Monitoring. NDT \& E International. 2016; 78: 199-210. https://doi.org/10.1016/j.ndteint.2016.10.007

16 Manka M, Martowicz A, Rosiek M, Stepinski T, Uhl T. Tunable interdigital transducers made of piezoelectric macro-fiber composite. Smart Materials and Structures. 2016;25(11):115022.

17 Manka M, Rosiek M, Martowicz A, Stepinski T, Uhl T. PZT based tunable Interdigital Transducer for Lamb waves based NDT and SHM. Mechanical Systems and Signal Processing. 2016;78:71-83. https://doi.org/10.1016/j.ymssp.2015.12.013

18 Manka M, Martowicz A, Rosiek M, Stepinski T, Uhl T. Ultrasonic piezoelectric transducer design and control methods. 2016. PL 222288 B1.

Received 2017-02-28

Accepted 2017-11-22

Available online 2017-12-18

\section{Michał MAŃKA, Ph D.}

Employed at Departament of Robotics and Mechatronics, on "AGH" University of Science and Technology, Cracow, Poland. $\mathrm{He}$ is the author of numerous publications concerning mechatronics, piezoelectric sensors and structural health monitoring.

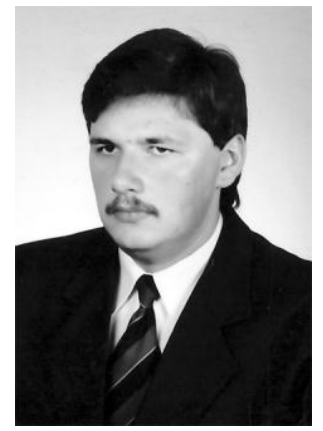

